\title{
Serum Levels of Soluble CD26, A Novel Prognostic Marker for Hepatitis E Infection
}

\author{
Alireza Rafiei, ${ }^{1}$ Abolghasem Ajami, ${ }^{1}$ Araz Mohammad Mirabi, ${ }^{2,}$ Mohammad Jafar Saffar, \\ Omolbanin Amjadi, ${ }^{1}$ Mohammad Reza Haghshenas, ${ }^{4}$ Farshideh Abedian, ${ }^{2}$ and Pouya \\ Khaje-Enayati $^{5}$ \\ ${ }_{2}^{1}$ Molecular and Cell Biology Research Center, Department of Immunology, Faculty of Medicine, Mazandaran University of Medical Sciences, Sari, IR Iran \\ ${ }_{3}^{2}$ Department of Immunology, Faculty of Medicine, Mazandaran University of Medical Sciences, Sari, IR Iran \\ ${ }^{3}$ Department of Infectious Diseases, Buali Hospital, Faculty of Medicine, Mazandaran University of Medical Sciences, Sari, IR Iran \\ ${ }_{5}^{4}$ Molecular and Cell Biology Research Center, Department of Microbiology and Virology, Faculty of Medicine, Mazandaran University of Medical Sciences, Sari, IR Iran \\ ${ }^{5}$ Student Research Committee, Faculty of Medicine, Mazandaran University of Medical Sciences, Sari, IR Iran \\ ${ }^{*}$ Corresponding author: Araz Mohammad Mirabi, Department of Immunology, Faculty of Medicine, Mazandaran University of Medical Sciences, Sari, IR Iran. Tel: +98-1133543614, \\ E-mail:mirabiaraz@gmail.com
}

Received 2015 July 19; Revised 2015 November 11; Accepted 2015 December 1.

\begin{abstract}
Background: Even without treatment, most acute hepatitis Evirus (HEV) infected patients resolve HEV but sometimes the disease leads to acute liver failure, chronic infection, or extrahepatic symptoms. The mechanisms of HEV pathogenesis appear to be substantially immune mediated. However, the immune responses to HEV are not precisely identified.

Objectives: This study aimed to evaluate the Th1/Th2 ratio by investigating serum soluble markers from Th1 and Th2 cells in acute HEV infected patients.

Patients and Methods: This case-control study included 35 acute HEV infected patients and 35 age and gender matched anti-HEV negative healthy controls. The serum levels of Interferon (IFN)- $\gamma$, IL-4, soluble CD26 (sCD26) and sCD30 were determined by the enzyme-linked immunosorbent assay.

Results: The results showed a significant difference in IFN- $\gamma$ and sCD26 $(\mathrm{P}<0.0001$ and $\mathrm{P}=0.001)$ yet not IL-4 and sCD30 $(\mathrm{P}=0.354$ and $\mathrm{P}=0.159$ ) between acute HEV patients and controls, respectively. There was a positive direct correlation between serum levels of sCD26 and IFN- $\gamma$ in acute $\mathrm{HEV}$ patients $(\mathrm{r}=0.64, \mathrm{P}=0.001)$. In addition, the ratio of $\mathrm{sCD} 26 / \mathrm{sCD} 30$ in the acute HEV group was more than two folds higher than in the HEV negative controls.

Conclusions: Acute HEV infection shows a pattern of Th1-type immune response, and the direct significant positive correlation between the serum level of sCD26 and IFN- $\gamma$ in acute HEV infected patients, suggests that the trend of sCD26 levels is a valuable marker for predicting hepatic inflammation in hepatitis $\mathrm{E}$.
\end{abstract}

Keywords: Acute Hepatitis, Hepatitis E virus, Soluble CD26, Soluble CD30, IL-4, IFN- $\gamma$

\section{Background}

Hepatitis E Virus (HEV) is the major cause of acute viral hepatitis in developing countries. Hepatitis E Virus virions are small, spherical, non-enveloped, positive-sense single-stranded RNA viruses, which belong to the genus hepevirus of the hepeviridae family (1). The virus transmits predominantly through the fecal-oral route, which is profoundly responsible for epidemics in tropical and subtropical countries (2). During outbreaks, the disease attack rate is more prevalent among young adults. Meanwhile, hepatitis E has been recently considered as a reemerging disease due to increased frequency of HEV seropositivity in industrialized countries $(3,4)$. Hepatitis E usually causes self-limiting disease with low mortality; however, acute liver failure, chronic infection, or extrahepatic symptoms are possible. The mechanisms of patho- genesis appear to be substantially immune-mediated. Although the infection is rarely progressed into its severe form, this can occur during pregnancy and in immunosuppressive conditions such as solid organ transplantation (4-6). Although chronic hepatitis E infection is not common, it is considered as a major clinical problem in immune compromised (7) and older patients (8).

Persistent HEV infections in immune compromised patients, suggest that HEV is controlled by adaptive immune responses. There are scarce studies that have investigated HEV-specific adaptive responses. Like other viral infections, both humoral and cellular immune responses, take part in the pathogenesis of HEV infection. It has been demonstrated that both IgM and IgG antibodies appear at disease onset such as jaundice and persist for variable periods. In

Copyright (C) 2016, Ahvaz Jundishapur University of Medical Sciences. This is an open-access article distributed under the terms of the Creative Commons Attribution-NonCommercial 4.0 International License (http://creativecommons.org/licenses/by-nc/4.0/) which permits copy and redistribute the material just in noncommercial usages, provided the original work is properly cited. 
spite of their neutralizing activities and being efficient for a long time, the exact role of humoral responses in protection against HEV reinfection remains unclear. Although hepatitis $\mathrm{E}$ is associated with a robust antibody response and this is the basis of HEV vaccine design strategy, cellular immune responses to HEV proteins develop in HEV-infected patients $(9,10)$. Regarding acute hepatitis E, there are a few studies that have shown HEV-specific lymphoproliferative responses of T cells (11) and higher production of interferon gamma by peripheral blood mononuclear cells (PBMCs), stimulated by recombinant HEV Open Reading Frame 2 (ORF2) and ORF3 proteins $(10,12)$. However, a few studies investigated T-cell immunity in HEV infection yet this issue is open and needs more consideration.

It has been shown that polarized human T helper type 1 (Th1) and T helper type 2 (Th2) cells not only produce different sets of cytokines, but also exhibit preferential expression of some activation markers (13-15). The CD30 is a member of the tumor necrosis factor (TNF) family, and appears to be preferentially expressed and released by human CD4+ and CD8+ T cells, producing predominantly Th2 cytokines (16). The CD26 is a cell surface glycoprotein with Dipeptidyl Peptidase IV (DPP IV) enzyme activity in the extracellular domain, correlating with the production of Th1-like cytokines in several diseases (17-19). After cellular activation, the soluble forms of $\mathrm{CD} 30$ (sCD30) and CD26 (sCD26) are released into the bloodstream. Therefore, analysis of CD26 and CD30 and their soluble forms has been proposed to be useful in discriminating Th1 and Th2 responses (19-21). However, there are scarce studies thus far to address Th1 and Th2- type responses in hepatitis E infection (22). Therefore, we here aimed to study Th1 and Th2 cytokine patterns in HEV-infected individuals.

\section{Objectives}

This study aimed to evaluate the Th1/Th2 ratio by investigating serum soluble markers from Th1 and Th2 cells in acute HEV infected patients.

\section{Patients and Methods}

\subsection{Study Population}

Seventy individuals were selected for this study. This population included 35 anti-HEV IgM positive patients and 35 age and gender matched anti-HEV negative controls. An informed consent was obtained from all participants. The current study was performed in accordance with ethical guidelines of the 1975 Declaration of Helsin$\mathrm{ki}$. In addition to the presence of IgM anti-HEV antibodies, patients were checked for clinical signs of hepatitis such as icterus, dark-colored urine, elevated alanine aminotransferase (ALT) and bilirubin levels in the serum, bile salts and pigments in the urine. The control group had the same epidemiological conditions as the patients, yet had negative anti-HEV IgM test results and no history of an illness resembling viral hepatitis, indicating their previous exposure to HEV. Individuals with infectious disease, pregnancy, chronic renal and liver diseases and those receiving blood or blood products within the last three months were excluded. In addition, all individuals were negative for hepatitis B surface antigen (Dia-Sorin, Saluggia, Italy), IgM anti-hepatitis A virus antibody (Hepanostika HAV IgM; Organon Teknika, Boxtel, the Netherlands), and anti-HCV antibody (Ortho-Clinical Diagnostics, Raritan, NJ, USA). The study protocol was approved by the medical ethics committee of Mazandaran University of Medical Sciences and conformed to the ethical guidelines of the declaration of Helsinki. Informed consent was obtained from each patient or their relatives.

\subsection{Serological Enzyme Immunoassays}

From eligible subjects, a 5-mL blood sample was drawn and serum was obtained by centrifugation at $1450 \mathrm{~g}$ for 15 minutes at $4^{\circ} \mathrm{C}$ and stored at $-80^{\circ} \mathrm{C}$ until further processing. Specific anti-HEV IgM antibody (anti-HEV) to immunodominant determinants derived from ORF2 and ORF3 of all the four HEV subtypes was measured using an enzyme immunoassay (DiaPro, Milan, Italy), according to the manufacturer's instructions. Serum levels of CD26, CD30, IFN- $\gamma$ and IL-4 were detected using commercially available sandwich enzyme-linked immunosorbent assay (ELISA) kits with paired cytokine-specific monoclonal antibodies, according to the manufacturer's recommended procedure (Bender Med Systems, Vienna, Austria). The detection limit for CD26 and CD30 were $7.26 \mathrm{pg} / \mathrm{mL}$ and $1.9 \mathrm{U} / \mathrm{mL}$, respectively.

\subsection{Statistical Analysis}

Significance analysis was performed for comparison of differences between HEV positive and non HEV-positive subjects using Mann-Whitney U test, independent t-test and Yate's correction of contingency where appropriate. Relationships between clinical variables and levels of soluble markers were evaluated by determining the Pearson correlation coefficient. A P $<0.05$ was considered to be significant. Linear regression analyses were carried out to determine a possible correlation between values of sCD30 and sCD26 and several biological markers such as IFN- $\gamma$ and IL-4.

\section{Results}

The basic characteristics of the study population are shown in Table 1 . There was no significant differences between patients with acute HEV infection and HEV negative controls with respect to age and gender $(\mathrm{P}=0.119$ and $\mathrm{P}=0.6$, respectively). All individuals had an age range of 11 to 25 years old and $48.6 \%$ of acute HEV infected patients and $40 \%$ of HEV negative subjects were males. In addition, there was no significant difference between the two groups in terms of location (urban or rural). As shown in Table 1, most of the patients exhibited higher sCD26 serum levels (104 - $536 \mathrm{pg} / \mathrm{mL})$ than the controls (16 - $324 \mathrm{pg} / \mathrm{mL}$ ), indicating significant differences $(\mathrm{P}=0.001)$. The median serum levels of CD30 were 48 and $40.9 \mathrm{U} / \mathrm{mL}$ in patients with HEV infection and HEV negative subjects, respectively, 
Rafiei A et al.

which shows no significant differences $(\mathrm{P}=0.159)$.

To have a clear picture of Th1- and Th2-type responses in acute HEV infection, serum levels of IFN- $\gamma$ and IL-4, with respect to Th1 and Th2 responses, were compared between the two groups. As shown in Table 1, IFN- $\gamma$ production was higher in acute HEV patients than HEV negative controls (median; 23.7 vs. $7.2 \mathrm{pg} / \mathrm{mL}, \mathrm{P}<0.0001$ ). Acute HEV patients also produced more serum IL-4 than the HEV negative controls yet these differences did not meet statistical significance (median; 7.1 vs. 5.5 U/mL, $\mathrm{P}=0.354$ ). The sCD26/sCD30 ratio was calculated for each individual, and the medians of ratios were then compared between acute HEV infection patients and HEV negative groups. The sCD26/sCD30 ratio was higher in acute HEV patients (5.17) than that of HEV negative subjects (2.22) and the difference was significant $(\mathrm{P}=0.001)$. On the other hand, the ratio of sCD26/sCD30 in the acute HEV group was more than two folds higher than the HEV negative group. Levels of sCD26 and sCD30 did not show any significant correlation with age, gender and location of each group.

\subsection{Effect of Acute Hepatitis E Virus Infection on the sCD26 and $s C D 30$}

To examine the impact of acute HEV infection on devel- opment of Th1 or Th2 response, correlation of serum levels of appropriate cytokines (IFN- $\gamma$ and IL-4) with expression of CD26 or CD30 were assessed. As shown in Figure 1A, a positive correlation was found only between the serum levels of sCD26 and IFN- $\gamma$ in acute HEV patients $(r=0.64, \mathrm{P}$ $=0.001)$. Nevertheless, the levels of sCD30 did not have any significant correlation with serum levels of IL-4 $(r=0.25, P$ $=0.37$ ) in this group (Figure $1 C$ ). There was no significant correlation between SCD26 or SCD30 and the levels of IFN- $\gamma$ or IL-4 in HEV negative subjects (Figure 1A and D).

Table 1. Basic Characteristics of Acute Hepatitis E Virus (HEV) Infected Patients and HEV Negative Controls ${ }^{\mathrm{a}, \mathrm{b}}$

\begin{tabular}{lccc}
\hline & Acute HEV Patients & Controls & P Value \\
\hline Age & $19.7 \pm 3.3$ & $18.4 \pm 3.2$ & 0.119 \\
Gender & & & \\
$\quad$ Male & 17 & 14 & 0.6 \\
$\quad$ Female & 18 & 21 & 0.6 \\
Location & & \\
$\quad$ Urban area & $14(40)$ & $16(45.7)$ & 0.8 \\
$\quad$ Rural area & $21(60)$ & $19(54.3)$ & \\
\hline $\mathrm{a}_{\mathrm{N}=35}$ & & \\
$\mathrm{~b}_{\text {Values are expressed as mean }}$ &
\end{tabular}

Figure 1. The Association Between sCD26 and IFN- $\gamma$ in Sera of Patients With Acute Hepatitis E Virus (HEV) Infection (a) and HEV Negative Subjects (b)
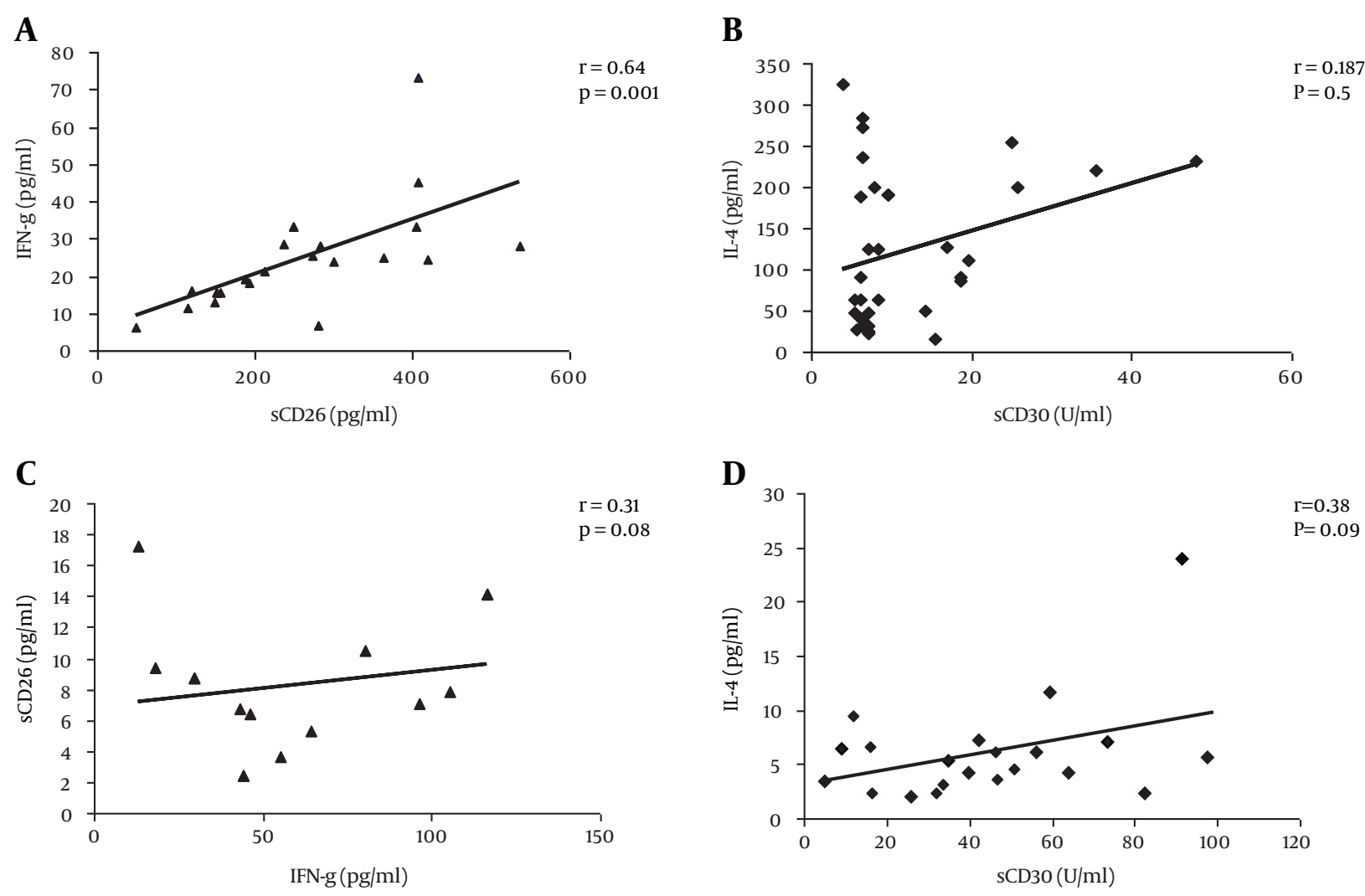

A, A direct positive correlation was seen between serum levels of IFN- $\gamma$ and sCD26 only in acute HEV infected subjects; C and D, The correlation between sCD30 and IL-4 in acute HEV patients or HEV negative subjects, respectively. $A, R=0.64, P=0.001 ; B, R=0.31, P=0.08 ; C, R=0.187, P=0.5 ; D, R=0.38, P=0.09$. 
Rafiei A et al.

\begin{tabular}{|c|c|c|c|}
\hline & Anti-HEV Positive $(n=35)$ & Anti-HEV Negative $(n=35)$ & P Value \\
\hline IFN- $\gamma(\mathbf{p g} / \mathbf{m L})$ & $23.7(6.3-73)$ & $7.2(4.3-48)$ & $<0.0001$ \\
\hline IL-4 (pg/mL) & $7.1(2.3-17.2)$ & $5.5(2.1-24)$ & 0.354 \\
\hline sCD26 $(\mathrm{pg} / \mathrm{mL})$ & $248(104-536)$ & $91(16-324)$ & 0.001 \\
\hline $\operatorname{sCD} 30(\mathrm{U} / \mathrm{mL})$ & $48.0(12.8-116.25)$ & $40.9(5-99)$ & 0.159 \\
\hline sCD26/sCD30 & $5.17(1.6-30)$ & $2.22(0.28-10.8)$ & 0.001 \\
\hline
\end{tabular}

${ }_{\text {a }}$ alues are expressed as median (range).

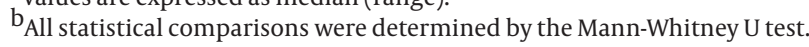

\section{Discussion}

To the best of our knowledge, the present work is the first study that evaluated the correlation between serum levels of sCD26 and sCD30 in which corresponding to Th1 and Th2-type immune responses on acute HEV infected patients in a HEV endemic area (23). The main findings of this study were increased serum levels of IFN- $\gamma$ and $s C D 26$ in acute HEV patients but not in HEV negative controls. Furthermore, T cell activation, occurring in acute HEV infected patients, was compared to HEV seronegative controls and demonstrated an increase in IFN- $\gamma$ production in acute HEV patients. T cell-mediated immune responses play a critical role in eliminating viral infections (24). Meanwhile, T-effectors responses may also determine the outcome of infection by mediating injury in virus-infected cells. Interferon- $\gamma$, a key cytokine of Th1-type immune response, plays an important role in protective immune response against viral infections (25-28).

It increases antigen presentation by antigen-presenting cells, in order to enhance MHC class I and costimulatory molecule expression on the cells. Gamma interferon enhances the antiviral state by increasing cytotoxic activity of NK, NKT, and CD8+ T cells on virusinfected cells (17). Moreover, it inhibits the development of Th2 type immune response by decreasing the production of Interleukin (IL)-4. Although Th1-type responses have been demonstrated to be correlated with hepatic inflammatory activity of viral hepatitis, via favoring the clearance of virus, Th2 cells may be associated with the persistence of those infection (29). Increased levels of IFN- $\gamma$ in acute hepatitis E infected patients compared with the controls might contribute to the successful clearance of the virus. In addition, no significant overproduction of IL-4 in acute HEV infected patients suggested the Th1/Th2 balance trend toward Th1 dominant immune response yet with a coincidental weak Th2 response in acute hepatitis $\mathrm{E}$ infection. These findings are in line with data obtained from other studies, which have shown a strong HEV-specific CD4+ and CD8+ T cell responses in the acute form of hepatitis $\mathrm{E}(12,30)$ and $\mathrm{B}$ infections (31).

The elevated levels of CD8+ T cells were observed in acute viral hepatitis-E in the study of TrehanPati et al. They also found an increase in CD38+CD69+ T cells, mRNA expression of IFN- $\gamma$, Tumor Necrosis Factor (TNF)- $\alpha$, IL-4 and down regulation of IL-2 and IL-10 in $\mathrm{CD} 4+\mathrm{T}$ cells in acute hepatitis E infection (32). Analysis of cytokine production or intracellular cytokine expression is routinely used to classify the immune response into Th1 and Th2 responses. It was demonstrated that Th1/Th2 responses are associated with hepatitis E infection and progression of fulminant hepatic failure (FHF) by detecting significant high levels of IFN- $\gamma$, IL-2, TNF- $\alpha$, and IL-10 cytokines (33). However, these are labor-intensive and time-consuming methods. Recently, analysis of CD26 and CD30, and their serum soluble forms have been proposed to be simple, useful, and efficient tools in discriminating Th1 and Th2 responses. These molecules are $\mathrm{T}$ cell activation markers associated with Th1- and Th2-related conditions, respectively $(13,15,34,35)$.

Analysis of serum sCD26 and sCD30 in acute HEV infection showed significantly higher levels of sCD26 in acute HEV patients compared with HEV seronegative controls. Moreover, the presence of a direct close correlation between serum levels of sCD26 and IFN- $\gamma$ in acute $\mathrm{HEV}$ patients suggests that $\mathrm{SCD} 26$ might be a surrogate indicator of Th1 immune response or a marker of $\mathrm{T}$ cell activation in acute HEV infection. Although CD8+ $\mathrm{T}$ cells and NK cells could produce IFN- $\gamma$, Th1 cells are more common sources of IFN- $\gamma$ production. Therefore, it would be logical to propose that higher production of IFN- $\gamma$ in acute HEV infected patients is reasonable for manifesting Th1 cell activation due to increased expression of CD26 molecules. Concordantly, this speculation was reported by Prabhu et al. they showed predominant enumeration of CD4+T cell in the liver of HEV infected patients (36). A significant increase in trend of HEV specific IFN- $\gamma$ producing T-cell response in Elispot of acute hepatitis E patients, which diminished after successful clearance of HEV infection (22).

In line with our case, other researchers highlighted specific $\mathrm{T}$ cell reactivity in acute hepatitis $\mathrm{E}$ infection, indicated by increased frequency of recombinant ORF2 protein specific IFN- $\gamma$ - secreting cells (12). Therefore, the 
elevated levels of IFN- $\gamma$, in acute HEV infection suggest that Th1-mediated effects may contribute not only to liver cell injury, but probably also play a major role in successful control of infection. In addition, higher levels of CD26 have been shown after successful treatment of chronic hepatitis B (37) and in remission of vasculitis (38). Interleukin (IL)- 4 is one of the key cytokines in Th2 response. It is a pleiotropic cytokine, which also shows prominent anti-inflammatory effects on Th1-driven inflammation by modulating macrophage activation and antagonizing the effects of IFN- $\gamma$. Therefore, IL-4 has as an important role, acts like a suppressor of the cellmediated response and increases the level of humoral immunity.

The present study showed that little increase in IL-4 levels in acute HEV patients indicates the activity of the Th2 phenotype in acute HEV infection, which is decisive for the production of neutralizing antiviral antibodies, resolution of infection, and inhibition of the overwhelming Th1-type inflammatory response. On the other hand, a shift to the Th1 cytokine environment favors the clearance of HEV infection in acute infected patients. There are concordant literature data showing very low levels of IL- 4 in the sera of patients with acute HBV infection (31). However, high expression/release of CD30 in acute HEV patients compared with healthy subjects possibly reflects the activation of $\mathrm{CD} 30$ harboring $\mathrm{CD} 4+$ or $\mathrm{CD} 8+\mathrm{T}$ cells during disease. Meanwhile, no significant correlation existed between the levels of sCD30 and IL-4 in acute HEV patients suggesting that CD4+ Th1 but not CD8+ T cells might be the main sources of sCD30-producing cells. Taken together, the key finding of this study was a direct significant positive correlation between the serum levels of sCD26 and IFN- $\gamma$ in acute HEV infected patients, which confirms that the trend of sCD26 levels is a valuable factor for predicting disease progression.

\section{Acknowledgments}

We appreciate the cooperation of the honorable staff of the infectious diseases department of Razi Hospital of Ghaemshahr, Buali hospital of Sari.

\section{Footnotes}

Authors' Contribution:All authors contributed to the study. Alireza Rafiei and Mohammad Jafar Saffar designed and conducted the research. Araz Mohammad Mirabi and Farshideh Abedian contributed to the data collection and carried out the assays. Alireza Rafiei and Abolghasem Ajami interpreted the results. Araz Mohammad Mirabi and Omolbanin Amjadi prepared the primary draft. All authors read and approved the final manuscript.

Funding/Support:This study was financially supported by the molecular and cell biology research center, Mazandaran University of Medical Sciences, with grant number MCBRC-MAZUMS- 89-52.

\section{References}

1. Pringle CR. Virus taxonomy--San Diego 1998. Arch Virol. 1998;143(7):1449-59. [PubMed: 9742051]

2. Emerson SU, Purcell RH. Hepatitis E virus. Rev Med Virol. 2003;13(3):145-54. doi: 10.1002/rmv.384. [PubMed:12740830]

3. Pischke S, Wedemeyer H. Chronic hepatitis $\mathrm{E}$ in liver transplant recipients: a significant clinical problem? Minerva Gastroenterol Dietol. 2010;56(2):121-8. [PubMed:20485250]

4. Aggarwal R, Naik S. Epidemiology of hepatitis E: current status. J Gastroenterol Hepatol. 2009;24(9):1484-93. doi: 10.1111/j.14401746.2009.05933.x. [PubMed: 19686410]

5. Haagsma EB, van den Berg AP, Porte RJ, Benne CA, Vennema $\mathrm{H}$, Reimerink JH, et al. Chronic hepatitis E virus infection in liver transplant recipients. Liver Transpl. 2008;14(4):547-53. doi: 10.1002/It.21480. [PubMed: 18383084]

6. Pal R, Aggarwal R, Naik SR, Das V, Das S, Naik S. Immunological alterations in pregnant women with acute hepatitis E. $J$ Gastroenterol Hepatol. 2005;20(7):1094-101. doi: 10.1111/j.14401746.2005.03875.x. [PubMed: 15955220]

7. Maylin S, Stephan R, Molina JM, Peraldi MN, Scieux C, Nicand E, et al. Prevalence of antibodies and RNA genome of hepatitis E virus in a cohort of French immunocompromised. J Clin Virol. 2012;53(4):346-9. doi: 10.1016/j.jcv.2012.01.001. [PubMed: 22293627]

8. Liu L, Liu Y. Analysis of acute to chronic hepatitis E: 6-10 year follow-up. Hepato-gastroenterology. 2010;58(106):324-5. [PubMed: 21661390]

9. Shata MT, Barrett A, Shire NJ, Abdelwahab SF, Sobhy M, Daef E, et al. Characterization of hepatitis E-specific cell-mediated immune response using IFN-gamma ELISPOT assay.J Immunol Methods. 2007;328(1-2):152-61. doi:10.1016/j.jim.2007.08.014. [PubMed: 17905301]

10. Srivastava R, Aggarwal R, Jameel S, Puri P, Gupta VK, Ramesh VS, et al. Cellular immune responses in acute hepatitis $E$ virus infection to the viral open reading frame 2 protein. Viral Immunol. 2007;20(1):56-65. doi: 10.1089/vim.2006.0053. [PubMed: 17425421]

11. Aggarwal R, Shukla R, Jameel S, Agrawal S, Puri P, Gupta VK, et al. T-cell epitope mapping of ORF2 and ORF3 proteins of human hepatitis E virus. JViral Hepat. 2007;14(4):283-92. doi:10.1111/j.13652893.2006.00796.x. [PubMed: 17381721]

12. Husain MM, Aggarwal R, Kumar D, Jameel S, Naik S. Effector T cells immune reactivity among patients with acute hepatitis E. $J$ Viral Hepat. 2011;18(10):e603-8. doi:10.1111/j.1365-2893.2011.01489.x. [PubMed: 21914082]

13. Krakauer M, Sorensen PS, Sellebjerg F.CD4(+)memoryT cells with high CD26 surface expression are enriched for Th1 markers and correlate with clinical severity of multiple sclerosis. J Neuroimmunol. 2006;181(1-2):157-64. doi:10.1016/j.jneuroim.2006.09.006. [PubMed:17081623]

14. Mosmann TR, Coffman RL. Heterogeneity of Cytokine Secretion Patterns and Functions of Helper T Cells. Adv Immunol. 1989;46:111-47. doi: 10.1016/s0065-2776(08)60652-5. [PubMed: 2528896]

15. Romagnani S, Del Prete G, Maggi E, Chilosi M, Caligaris-Cappio F, Pizzolo G. CD30 and type 2 T helper (Th2) responses.J Leukoc Biol. 1995;57(5):726-30. [PubMed: 7759952]

16. Del Prete G, De Carli M, Almerigogna F, Daniel CK, D'Elios MM, Zancuoghi G, et al. Preferential expression of CD30 by human CD4+ T cells producing Th2-type cytokines. FASEB J.1995;9(1):81-6. [PubMed: 7821763]

17. Gattoni A, Parlato A, Vangieri B, Bresciani M, Derna R. Interferon-gamma: biologic functions and HCV terapy (type I/II) (2 of 2 parts). Clin Ter. 2006;157(5):457-68. [PubMed: 17147054]

18. Yang SS, Fu LS, Chang CS, Yeh HZ, Chen GH, Kao JH. Changes of soluble CD26 and CD30 levels correlate with response to interferon plus ribavirin therapy in patients with chronic hepatitis C. J Gastroenterol Hepatol. 2006;21(12):1789-93. doi: 10.1111/j.14401746.2006.04677.x. [PubMed: 17074015]

19. Ajdary S, Jafari-Shakib R, Riazi-Rad F, Khamesipour A. Soluble CD26 and CD30 levels in patients with anthroponotic cuta- 
neous leishmaniasis. J Infect. 2007;55(1):75-8. doi: 10.1016/j. jinf.2006.12.005. [PubMed: 17241668]

20. Monsalve-de Castillo F, Romero TA, Estevez J, Costa LL, Atencio R, Porto L, et al. Concentrations of Cytokines, Soluble Interleukin-2 Receptor, and Soluble CD30 in Sera of Patients with Hepatitis B Virus Infection during Acute and Convalescent Phases. Clin Vaccine Immunol. 2002;9(6):1372-5. doi: 10.1128/cdli.9.6.13721375.2002.

21. Foschi FG, Gramenzi A, Castelli E, Cursaro C, Pagani S, Margotti $\mathrm{M}$, et al. Soluble CD30 serum level in HCV-positive chronic active hepatitis: A surrogate marker of disease activity? Cytokine. 2000;12(6):815-8. doi:10.1006/cyto.1999.0653. [PubMed:10843771]

22. Tripathy AS, Das R, Rathod SB, Arankalle VA. Cytokine profiles, CTL response and $T$ cell frequencies in the peripheral blood of acute patients and individuals recovered from hepatitis $\mathrm{E}$ infection. PLoS One. 2012;7(2):e31822. doi:10.1371/journal.pone.0031822. [PubMed: 22347438]

23. Saffar MJ, Farhadi R, Ajami A, Khalilian AR, Babamahmodi F, Saffar H. Seroepidemiology of hepatitis E virus infection in 2-25-year-olds in Sari district, Islamic Republic of Iran. East Mediterr Health J. 2009;15(1):136-42. [PubMed: 19469436]

24. Okamoto H. Culture systems for hepatitis E virus. J Gastroenterol. 2013;48(2):147-58. doi: 10.1007/s00535-012-0682-0. [PubMed: 23104469]

25. Belardelli F. Role of interferons and other cytokines in the regulation of the immune response. APMIS. 1995;103(3):161-79. [PubMed: 7538771]

26. Muller U, Steinhoff U, Reis LF, Hemmi S, Pavlovic J, Zinkernagel $\mathrm{RM}$, et al. Functional role of type I and type II interferons in antiviral defense. Science. 1994;264(5167):1918-21. [PubMed: 8009221]

27. Mishra N, Arankalle VA. Association of polymorphisms in the promoter regions of TNF-alpha (-308) with susceptibility to hepatitis E virus and TNF-alpha (-1031) and IFN-gamma (+874) genes with clinical outcome of hepatitis $\mathrm{E}$ infection in India. J Hepatol. 2011;55(6):1227-34. doi: 10.1016/j.jhep.2011.03.023. [PubMed: 21703188]

28. Krain LJ, Nelson KE, Labrique AB. Host immune status and response to hepatitis E virus infection. Clin Microbiol Rev. 2014;27(1):139-65. doi:10.1128/CMR.00062-13. [PubMed:24396140]

29. Jiang R, Feng X, Guo Y, Lu Q, Hou J, Luo K, et al. T helper cells in patients with chronic hepatitis B virus infection. China Med J.

\section{2;115(3):422-4}

30. Suneetha PV, Pischke S, Schlaphoff V, Grabowski J, Fytili P, Gronert A, et al. Hepatitis E virus (HEV)-specific T-cell responses are associated with control of HEV infection. Hepatology. 2012;55(3):695708. doi: 10.1002/hep.24738. [PubMed: 22006345]

31. Penna A, Del Prete G, Cavalli A, Bertoletti A, D'Elios MM, Sorrentino $\mathrm{R}$, et al. Predominant T-helper 1 cytokine profile of hepatitis $B$ virus nucleocapsid-specific T cells in acute self-limited hepatitis B. Hepatology. 1997;25(4):1022-7. doi: 10.1002/hep.510250438. [PubMed: 9096614]

32. TrehanPati N, Sukriti S, Geffers R, Hissar S, Riese P, Toepfer T, et al. Gene expression profiles of $\mathrm{T}$ cells from hepatitis $\mathrm{E}$ virus infected patients in acute and resolving phase. J Clin Immunol. 2011;31(3):498-508. doi: 10.1007/s10875-010-9506-2. [PubMed: 21287396]

33. Saravanabalaji S, Tripathy AS, Dhoot RR, Chadha MS, Kakrani AL, Arankalle VA. Viral load, antibody titers and recombinant open reading frame 2 protein-induced $\mathrm{TH} 1 / \mathrm{TH} 2$ cytokines and cellular immune responses in self-limiting and fulminant hepatitis e. Intervirology. 2009;52(2):78-85. doi: 10.1159/000214862. [PubMed: 19401616]

34. Hoshimoto K, Ohta N, Ohkura T, Inaba N. Changes in plasma soluble CD26 and CD30 during pregnancy: markers of Th1/ Th2 balance? Gynecol Obstet Invest. 2000;50(4):260-3. [PubMed: 11093050]

35. Nakao K, Nagake Y, Okamoto A, Ichikawa H, Yamamura M, Makino H. Serum levels of soluble CD26 and CD30 in patients on hemodialysis. Nephron. 2002;91(2):215-21. [PubMed:12053056]

36. Prabhu SB, Gupta P, Durgapal H, Rath S, Gupta SD, Acharya SK, et al. Study of cellular immune response against Hepatitis $\mathrm{E}$ virus (HEV). J Viral Hepat. 2011;18(8):587-94. doi: 10.1111/j.13652893.2010.01338.x. [PubMed: 20579277]

37. Alavi-Moghaddam M, Alavian SM, Aalaei-Andabili SH, Eslami-Far A. Do the initial serum level changes of $\mathrm{SCD} 26$ have ability to predict successful treatment with IFN-alpha among naive chronic hepatitis B patients? Vaccine. 2011;29(48):9093-7. doi: 10.1016/j. vaccine.2011.08.094. [PubMed:21893143]

38. Schonermarck U, Csernok E, Trabandt A, Hansen H, Gross WL. Circulating cytokines and soluble CD23, CD26 and CD30 in ANCAassociated vasculitides. Clin Exp Rheumatol. 2000;18(4):457-63. [PubMed: 10949720] 